\title{
Medullary Cystic Kidney Disease Type I
}

National Cancer Institute

\section{Source}

National Cancer Institute. Medullary Cystic Kidney Disease Type I. NCI Thesaurus. Code C123171.

An inherited form of cystic kidney disease that leads to fibrosis and impaired renal function as a result of defects in the MUC1 gene, which encodes mucin 1. 